\title{
ANNUAL MEETING SHORT COURSE
}

For the first time, the Society will offer in conjunction with its 1982 Annual Meeting, a short course for professional development. It is entitled: "Liquid Phase Epitaxy Techniques" and will occupy two full day sessions on Nov. 3 and Nov. 4.

Taught by Ralph Dawson of Sandia National Laboratories, the course will present practical aspects of epitaxial crystal growth with emphasis on application to III-V compound semiconductors. The "nuts and bolts" emphasis of the course should benefit those who wish to be involved with liquid phase epitaxy in the laboratory, but have little experience with the problems involved.

\section{AREAS TO BE COVERED}

Dawson said the areas to be covered include basic relevant thermodynamics, materials for which the technique is applicable, various systems' designs and growth procedures, growth kinetics and some approaches to elementary characterization. The technique will be compared and contrasted with competing systems, namely chemical vapor deposition and molecular beam epitaxy. If there is sufficient interest, a special evening session will be arranged to discuss the needs and problems of those who are enrolled in the course.

Dawson, who did his graduate work in electrical engineering at the University of Southern California, has been involved in liquid phase epitaxial growth of semiconductor material for 17 years, including eight years at Bell Laboratories and five at Sandia National Laboratories. He has used the technique for the growth of a wide range of III- $V$ compounds, including GaAs, AlGaAs, GaP, InP, and $\mathrm{GaSb}$, for a broad range of device applications including Gunn devices, light emitting diodes, field effect and bipolar transistors, lasers and optical detectors.

\section{HOW TO ENROLL}

Registration materials are being forwarded to the Society's members with Annual Meeting materials. Non-members are invited to participate, and should contact the Society's Secretariat, Ernest $M$. Hawk, 110 Materials Research Laboratory, University Park, PA 16802.

Advance registration of members is encouraged. Roughly fifteen enrollees are required if the session is to be viable. There is no practical upper limit however, so that registration at the meeting itself will be possible, given a minimum preregistered number of attendees. 